\title{
Becoming none but tradesmen: lies, deception and psychotic patients*
}

Christopher James Ryan, Greg de Moore and Martyn Patfield
Westmead Hospital, Westmead, Australia, and Cumberland Hospital, North Parramatta, Australia is

\section{Abstract}

Is there ever any reason for a doctor to lie to a patient? In this paper, we critically review the literature on lying to patients and challenge the common notion that while lying is unacceptable, a related entity - 'benevolent deception' is defensible. Further, we outline a rare circumstance when treating psychotic patients where lying to the patient is justified. This circumstance is illustrated by a clinical vignette.

\section{Lying to patients}

What do we mean by lying to a patient? The ethics literature concerned with lying to patients devotes a great deal of energy to discovering the definition of a lie. For this reason any examination of the issue must begin with a clear definition. For the purposes of this paper, we mean more than just the direct imparting of false information. We also mean the deliberate decision to withhold from the patient information, which, the doctor knows, would have a special significance to the patient. Using this definition, lying to a cancer patient who asks about his or her diagnosis, will include falsehoods far beyond just telling the patient that he or she does not have cancer. It will also include half-truths designed to deceive, such as the reply that he has a metaplasia or evasions with the same goal, such as saying untruthfully that there is not yet enough information to know. In everyday language of course a distinction is made between lies, half-truths and evasions, however, for reasons we shall outline shortly, we do not feel that such distinctions should play a significant part in ethical debate about these issues and therefore will refer to all as lies.

The ethical issues surrounding a doctor's ability to lie to a patient have undergone a revolution in the last

\section{Key words}

Honesty; lying; intentional deception; psychosis; truth-telling.

*'Let me have no lying; it becomes none but tradesmen' $A$ Winter's Tale IV iii
20 years. This period has coincided with an increased $\bar{\varnothing}$ awareness of the issue of medical ethics generally, ${ }_{-}$ and this awareness has been fostered by greater is public education, a greater public acknowledgement $N$ of individual rights and the emergence of medical $\mathrm{O}$ consumer groups and patient advocates $(1,2)$.

Before this it was generally believed that it was $\vec{D}$ acceptable to lie to patients in some circumstances and, indeed, it was often regarded as good ethical and clinical practice (3). The rationale for this belief $\stackrel{\bullet}{\bullet}$ was rarely spelt out, but when it was, it was usually based on the physician's maxim: primum non nocere above all do no harm (4-6).

More formally the argument supporting lying to patients might be represented like this:

1. On some occasions, to tell a patient the truth will $\overline{\vec{a}}$ cause him harm.

2. Doctors should not cause harm to their patients.

therefore

3. On these occasions, doctors should not tell their patients the truth.

Generally the argument comes complete with a 음 clinical vignette to act as a convincing illustration. Usually this involves an elderly patient with a을. terminal cancer and only a short time to live. It is o argued that no useful purpose is served by telling this patient of her fate and that this would only increase 0 her suffering. Better, if necessary, to keep her in the $\omega$ dark, with a 'white' lie. The pervasiveness of this doctrine was illustrated by several studies in the fifties and sixties confirming that doctors tended not $\mathbb{D}$ to inform their cancer patients of their diagnoses ${ }^{?}$ $(7,8)$.

Today, at least regarding telling patients they have cancer, the situation seems to have changed (9). $\frac{\text { o }}{\Phi}$

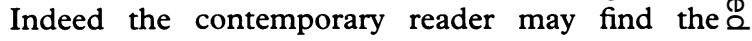
traditional position extremely puzzling, and marvelo that it held sway as long as it did. It may be that its $\delta$ survival owed much to the fact that it was so rarelyo spelt out and that it relieved the doctor from the extremely distressing business of imparting terrible 
news. Whatever the reason for its former attractiveness, the position has few supporters in today's medical ethics literature.

Two related objections are generally put forward against the traditional opinion. The first re-examines the premises of the traditional argument, while the second introduces the concept of autonomy.

The first objection calls into dispute both premises of the argument. First it suggests that premise 1 should actually read:

1: On some occasions to tell the patient the truth will cause more harm than it will cause to tell him a lie (10).

After all, to withhold from the cancer patient the knowledge of his imminent demise may mean that he is deprived of an opportunity to get his affairs in order, to settle old scores, or simply to say goodbye. Further, it is likely that the patient will find out or guess that he is dying anyway (11), so that nothing will be gained and the patient will lose the trust that he has placed in his family and in his doctor. Lastly, there is little doubt that most patients cope well with the knowledge that they are shortly to die and some are actually comforted by it (12). All in all it is far from clear that even in this illustrative case the patient gains any net benefit from the doctor's deceit (13).

Secondly, this objection disputes the wording of premise 2 . Surely the doctor's responsibilities extend beyond only the patient she is currently seeing. She must consider the welfare of the community and other patients as well. Considering these broader responsibilities premise 2 becomes:

\section{2: Doctors should not cause harm.}

If it were to become generally known that doctors deceive their dying patients then other patients who fear they may be dying (perhaps erroneously) will lose trust in their doctors and perhaps assume the worst. Thus, the lie to this patient causes harm to other patients.

With the substitution of these new premises then, the doctor is left having to make an extremely difficult decision. How is she to know on which occasions her lie will cause more good than harm? She cannot, the objection goes, there are just too many factors to consider and she is better off always to take the option that is most likely to cause least harm. She should always tell the truth (10).

The second objection comes to the same conclusion, but from a slightly different angle. It introduces the concept of the right to autonomy. Normally, adult human beings have the capacity to make decisions about their lives and so direct the course of their own fate. This objection holds that people have the right to exercise that capacity whether it causes them harm or not. One cannot properly exercise one's autonomy if one is not in possession of all available information that might influence one's decisions. To lie to, or withhold information from, a patient, is to restrict his autonomy and the doctor has no right to do this (14). She must always tell the truth.

These objections, or at least the sentiments behind them, have proved very persuasive. Few, if any, writers now suggest that directly lying to a patient is ethically justifiable in any circumstance, except at the extremes of trivial matters and utter crises (15).

A few writers do, however, continue to maintain that while a direct lie is wrong, 'benevolent deception' is permissible $(16,17)$. This entity is distinguished from lying in the everyday sense and includes distortions, evasions and any attempt to fool a patient that falls short of an outright lie. This manoeuvre has a seductive attractiveness that probably relates to how well it fits with the morality of the 'white lie' that we learned at our mother's knee. Indeed, even authors who argue cogently against it seem to find it difficult entirely to escape its spell (18). In the long run, however, benevolent deception will do little to quell the objections to untruth reviewed above. Ultimately, the patient is still deprived of information that he has a central concern with and he is still likely to suffer harmful consequences and be robbed of his autonomy.

We believe that widespread use of the term 'benevolent deception' is ultimately pernicious. The term is akin to others such as 'ethnic cleansing' for 'genocide' and 'explosive device' for 'bomb'. It removes the emotional tone that the word normally carries and thus allows us to use it without setting off the moral alarm bells that contemplating the action would normally entail. Just as it is easier to neutralise a target than it is to kill people, so it becomes easier benevolently to deceive than to lie. In the end the result, in both cases, is the same. Benevolently to deceive is to lie.

\section{Lying to psychotic patients}

Psychosis is generally held to be an umbrella term encompassing the presence of one or more delusions, hallucinations or profoundly disorganised thoughts. A delusion is a false, unshakeable idea or belief which is out of keeping with the patient's educational, cultural and social background and which is held with extraordinary conviction and subjective certainty (19).

We believe that the psychotic patient will, on rare occasions, present a special case where it will be ethically justifiable to lie in circumstances that are clearly neither trivial nor critical. To demonstrate this, we will use a vignette to revisit the objections to the traditional view.

Imagine that you are a psychiatrist in a general hospital. One day the dermatology team consults you about a female patient, whom they believe has 
delusions of infestation. Delusional infestation is a relatively rare syndrome where the patient is wrongly convinced that she harbours some as yet undiscovered bug in her skin. This belief is usually intense, completely preoccupying and unamenable to any sort of persuasion, though it frequently responds completely to antipsychotic medication. The patient may be tortured by her conviction and endlessly seek relief from her supposed condition. Apart from this belief the patient typically has no other delusional ideas and is in all other respects completely normal (20).

Unfortunately, the dermatology team is not sure of the diagnosis and feel they need your opinion. As they describe the case, they caution you not to reveal to the patient that you are a psychiatrist. They tell you that the patient has been seen in two other hospitals previously and on both occasions left as soon as an attending psychiatrist identified his profession. Telephone calls to your colleagues confirm that no matter how carefully they informed the patient that they were psychiatrists she had refused to see them and no psychiatric assessment had so far been possible. The patient is greatly tormented by her symptoms.

Assume that this is the situation; if you do not see her, she will continue to suffer perhaps indefinitely, but if she learns you are a psychiatrist then she will refuse to have anything to do with you.

Reluctantly you decide to attend her. However, just as you extend your hand in introduction the patient looks up at you expectantly: 'Are you a shrink?' she asks. What are you to say? Should you lie to her?

One response would be to tell her that you are a specialist in emotional problems. Then, without telling any further untruths, you complete your assessment. You then prescribe an antipsychotic medication, skirting around details of its method of action, and three weeks later she returns to see you completely recovered. Certainly this is a solution that psychiatrists, imagining themselves in this position, commonly put forward. Notice, however, that since the patient would clearly attach a special significance to whether or not you are a psychiatrist and as you are deliberately withholding this information, this deception is still a lie by our strict definition. So too is your failure to reveal the mechanism of action of the antipsychotic. However, are they justifiable lies?

It will not be difficult to justify your lie using the traditional argument as initially framed. Had you told the patient the truth, you knew, with a high degree of certainty, that she would refuse to speak with you further, leave the outpatient department and, receiving no treatment for her complaint, continue to be deeply troubled by her delusions. However, how does this lie stand up to the objections that found the lie to the cancer patient indefensible?
Recall that the first objection re-examined the premises of the traditional argument and demanded that we weigh the good our actions achieve against the harm they do. In the cancer patient scenario the objection went on to assert that the questionable goodo done by deception was far exceeded by all the harms 흐 that flowed from it. Here, however, this does not $\frac{\bar{c}}{7}$ appear to be the case. It is difficult to imagine in what $\stackrel{\mathbb{Q}}{\Omega}$ way this patient would benefit from knowing the truth about your profession. It does not seem that it will ${ }^{\infty}$ interfere with her life or harm her in any way beyond $\stackrel{\circ}{\circ}$ leading to her successful treatment. Although there $\overrightarrow{\vec{\omega}}$ remains the possibility that she will discover the truth $\stackrel{\sigma}{\omega}$ and lose faith in her doctors, she doesn't seem to have any faith in psychiatrists as it is, and the dermatologists, according to the scenario, can't do much for her alone. There is also no real concern about the possibility of this type of deception becoming $N$ generally known. First, it seems unlikely that it would 음 become generally known, as delusions of infestation $\rightarrow$ are relatively rare and, secondly, even if it did, those $\frac{}{0}$ afflicted with the syndrome are, almost by definition, unable to recognise themselves as a member of the $\overrightarrow{0}$ group that may be misled in this manner.

What of the objection based on autonomy? Here it does not matter whether the good outweighs the harm; if the patient's autonomy is violated, the doctor is wrong to lie. Autonomy refers to the ability of adult human beings to make their own decisions $\frac{}{\mathbb{D}}$ about their lives. One cannot exercise one's autonomy, however, if one is being misled, hence it was wrong for the doctor to mislead the patient with cancer. In this case, however, even before you have lied to the patient, she is being misled by another source. She is suffering from a delusion. A delusion is a fixed false belief that is arrived at because the sufferer has a mental illness. It is a manifestation of a 3 . malfunction within the brain, not simply a false conclusion based on false premises or arrived at $\bar{\xi}$ through flawed reasoning. The patient is already 0 being misled by her illness. She suffers from the delusion that she is infested with bugs. It is the deceit she is subjected to at the hands of the delusion that leads her to her decision not to see a psychiatrist. It or is hardly surprising she refuses to see a psychiatrist $-N$ she believes that she has a skin condition. Because $N$ she is being fooled by her illness, the patient is 0 incompetent to make a decision about seeing you and the decision not to see you is not an autonomous $\frac{\varnothing}{\Phi}$ decision. Her autonomy has already been breached $\stackrel{?}{-}$ by the false contents of her delusion and your lie 0 causes no additional breach in this limited area. The $\overline{0}$

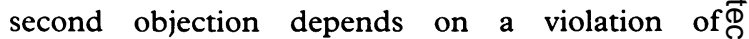
autonomy; if none occurs, the objection dissolves. $\mathbb{\mathbb { D }}$

Notice, too, that in providing successful treatment $\frac{a}{\sigma}$ as a consequence of your lie, you also ultimately remove the delusion that was deceiving the patient $\delta$ and limiting her autonomy. Since maximisation of autonomy is a legitimate good, this may be added to을 the positive side of the utilitarian ledger. 
Using this example, it is now possible to outline a number of conditions, which, if met in a particular circumstance, would justify lying to the patient with a psychotic illness.

1. As a direct result of the patient's delusion she is incapable of making an informed decision on a particular matter, $\mathbf{P}$.

2 . If the patient were to make a particular decision regarding $\mathrm{P}$, a significant degree of harm would accrue, clearly outweighing any foreseeable good.

3. The doctor believes, with a high degree of certainty, that the patient will make that decision regarding $P$, unless she lies to or in some way deceives the patient about $P$.

4. No other course of action is practicable.

The criterion that the patient be suffering a delusion is crucial. It is not difficult to think of many instances where a usually competent patient's judgment may be temporarily impaired by illness. A patient, for example, may be in severe pain or greatly fear for his future and this may lead him to make a decision that the clinician regards as unwise. In these circumstances though, the patient has not come to his belief as a direct result of his illness but, rather, has come to his own autonomous decision in the context of his illness. $\mathrm{He}$ is not being directly deceived by his illness, his illness has just created a situation where it is difficult to make a decision. A delusion creates a situation where it is temporarily impossible for the individual to make an autonomous decision, because he is misled by the content of the delusion. Other conditions such as dementia and childhood may render one incapable of autonomous decisions for other reasons, but these are beyond the scope of this paper.

It is important to notice that the content of the proposed falsehood is strictly limited. Only matters directly relating to the content of the delusion that influence decisions may be addressed. In this case, for example, you are not at liberty to deceive the patient about some other matter, say the side-effects of antipsychotics. You may believe that the small risk of serious or irreversible side-effects associated with antipsychotics is more than offset by the benefit in terms of symptom relief, however, if the patient asks if there is any slight risk of a serious or irreversible side-effect, then you must reply truthfully that there is. Nothing about her illness makes her incompetent on the side-effect front. You may, however, lie about the mode of action of antipsychotics - namely that they reverse psychoses - because it is highly likely the patient will refuse to take an antipsychotic for the same reasons she would refuse to see you.

These conditions impose a heavy burden on the about-to-be-deceitful doctor. The decision on whether or not to lie will pivot on the degree of harm that the doctor feels the patient will come to, if not deceived. Obviously decisions about whether the future harm will be significant or not defy easily spelt out guidelines. Every lie to a patient has the potential to damage the assumption of trustworthiness that every patient makes when he sees his doctor and therefore the decision to lie, even in this sort of circumstance, should be made only after careful consideration. The point is, however, that the significance of the harm may not necessarily be of life and death proportions.

Condition four ensures that lying is the last resort. In our example we assumed that if you did not see the patient, she could not be treated. In the real world, however, it might have been possible to assess the patient via proxy and to convince the dermatologists that with your help they could see her and begin treatment themselves.

Furthermore, as soon as any of these conditions fail to apply, the doctor is again required to be truthful. Thus, when your patient returns in three weeks no longer influenced by a delusion, you are under an obligation carefully to explain to the patient the nature of her illness, its treatment and that you are in fact a psychiatrist after all. If now, she still decides to take her leave, then she is exercising her autonomy unfettered by illness. Chances are of course she will not, because not only has your lie allowed a chance to treat her, but it has also given you a chance to establish rapport and, paradoxically, build trust with her.

There is one final objection to lying even in these circumstances that must be addressed. Though rarely articulated in the literature, it is commonly held among clinicians. It proclaims that, regardless of the consequences and in spite of the issue of autonomy, to lie in itself is wrong and you simply should not do it. There is, however, a strong and well known counter to this view. The counter imagines the following scenario.

One night you are sitting at home, watching television, when there is a knock at the door. When you open the door, a young boy bolts past you and immediately dives under your couch. Just as you are trying to find out what's happening there is another knock. This time you are confronted by a tall dark figure in a long flowing cape. In his right hand, a dagger glints in the light from the hallway behind you. The figure explains that he is looking for a small boy, whom he intends to murder with the knife.

'Have you seen such a boy?', the figure asks. You know that either you must lie or the boy will be murdered.

In this situation, few people would direct the spectre to the floor beneath the couch. Rather, most would agree the right option is blatantly to deny all knowledge of the child and to send the murderer on his way. So it seems, that at least in some circumstances, it is not always wrong to lie.

Such special cases are likely to arise only very rarely. Together, the authors have been only able to produce six or seven reasonably common clinical scenarios where the above conditions might be met and where lying would be justified. For example, you 
have just decided that a suicidal patient with a major depression will require involuntary admission. $\mathrm{He}$ is a very large man, and has the delusional belief that he is unworthy of treatment. He has already clearly indicated he would rather flee than come into hospital, so you have organised for the hospital security-guards to escort him to a secure unit. While you wait for them, he asks you what the delay is about. You believe that if you tell him it is because you've sent for reinforcements he will try to leave immediately. Though you do not think he will be able to escape, you do feel that without securityguards both he and staff members may be injured in the ensuing struggle. In this circumstance we do not think it would be unethical to tell him, if pushed, that you are waiting for a blood result.

In the majority of clinical practice, however, these conditions will not be met and lies or deception will be unjustified and wrong. We cannot, for example, envisage a situation where a patient, whom you believe has a clear diagnosis of schizophrenia, should not be informed of his diagnosis early in his treatment. Green (21) found that only 58 per cent of his sample of psychiatrists always or usually told their patients of a diagnosis of schizophrenia. Nothing written here should be seen as supporting the deception of the other 42 per cent.

Lastly, why say you are a specialist in emotional problems? If this is a lie, why not tell the patient that you are a dermatologist and be done with it? As far as the patient's autonomy is concerned there is no difference between these replies, normally they would both breach the patient's autonomy and therefore one is no more or less ethical than the other. Eventually, though, the patient will be told the truth and because she will most likely see 'half-truths' as more acceptable than what are commonly regarded as lies, it will probably be easier to maintain a rapport with her if you have told such a 'half-truth'. The specialistin-emotional-problems line is most likely to lead to a successful clinical outcome and therefore it is preferable both on clinical and utilitarian grounds.

\section{Conclusion}

The consensus of the literature now holds that it is wrong to lie to patients in all but life and death situations. This consensus derives from powerful arguments suggesting that either the lie will cause more harm than good or it will violate the patient's right to make an autonomous decision. Manoeuvres sanctioning 'benevolent deception' do nothing to circumvent these arguments. Occasionally, however, in cases involving psychotic patients, these arguments lose their power. In these cases the good done by the lie clearly outweighs the harm and because the patient's autonomy is already compromised by illness no further violation of autonomy takes place. In these rare cases doctors are justified in lying.to their patients.
Christopher fames Ryan, MBBS, FRANZCP, is Consultant Liaison Psychiatrist, Department of Psychiatry, Westmead Hospital, Westmead, NSW, Australia. Greg de Moore, MBBS, FRANZCP, is Consultant Liaison Psychiatrist, Department of Psychiatry, Westmead Hospital, Westmead, NSW, Australia and Martyn Patfield, MBBS, is Psychiatry Registrar, Cumberland Hospital, North Parramatta, NSW, Australia.

\section{References}

(1) Mitchell K R, Terence J L. Bioethics for medical and $\overrightarrow{0}$ health professionals. Wentworthfalls, NSW: Social Science Press, 1991.

(2) Beauchamp T, Childress V, eds. Principles of biomedical ethics [3rd ed]. Oxford: Oxford University Press, 1989.

(3) Lipkin M. On lying to patients. Newsweek 1979 Jun 4: 13, reprinted Mappes T A, Zembaty J S. Biomedical N ethics [3rd ed]. New York: McGraw Hill, 1991.

(4) Percival T. Medical ethics. See reference (2): 382.

(5) Meyer B C. Truth and the physician. Bulletin of the New York Academy of Medicine 1969; 45: 59-71.

(6) Henderson H J. New England journal of medicine 1935; 112: 819 .

(7) Fitts W T, Ravdin I S. What Philadelphia physicians tell their patients with cancer. Fournal of the American of Medical Association 1953; 153: 901-904.

(8) Oken D. What to tell cancer patients: A study of medical attitudes. In: Gorovitz S, ed. Moral problems in medicine. Englewood Cliffs, New Jersey: Prentice-Hall, 1976 (Oken's study was first published in 1967).

(9) Novack D H, Plummer R, Smith R L. Changes in physicians' attitudes toward telling the cancer patient. Fournal of the American Medical Association 1979; 241 : 897-900.

(10) Buchanan A. Medical paternalism. Philosophy and public affairs 1978; 7: 371-390.

(11) Kübler-Ross E. On death and dying. New York: Macmillan, 1969.

(12) Kübler-Ross E, ed. Death: the final stage of growth. Englewood Cliffs, New Jersey: Prentice-Hall, 1975.

(13) Bok S. Lying: moral choice in public and private life. New York: Pantheon, 1978.

(14) Robinson J A T. The patient's right to know. Proceedings of the Royal Society of Medicine 1973; 66: 536-537.

(15) Higgs R. On telling patients the truth. In: Lockwood $\mathrm{M}$, ed. Moral dilemmas in medicine. Oxford: Oxford $\mathrm{N}$ University Press, 1985.

(16) Jackson J. Telling the truth. Fournal of medical ethics 1991; 17: 5-9.

(17) Elin J S. Lying and deception: the solution to a dilemma in medical ethics. Westminster Institute review 1981; 1: 3-6. Reprinted in Mappes T A, Zembaty J S. Biomedical ethics [3rd ed]. New York: $\stackrel{?}{+}$ McGraw Hill, 1991.

(18) Bakhurst D. On lying and deceiving. fournal of medical ethics 1992; 18: 63-66.

(19) Sims A. Symptoms in the mind. An introduction to descrip- $\frac{?}{\mathbb{1}}$ tive psychopathology. London: Baillière Tindall, 1988. 응

(20) Morris M. Delusional infestation. British journal of psychiatry 1991; 159 [suppl 14]: 83-87.

(21) Green R, Gantt A. Telling patients and families the psychiatric diagnosis: a survey of psychiatrists. Hospital and community psychiatry 1987; 38: 666-668. 